加里东运动在粤西的影响及其性質的一些看法和观点

\title{
刘以宣苏广麇楊光復
}

\section{一 問題的提出}

中国东南部前泥盆紀地稹的发展特征反 其构造性盾，是长期以来中外地稹学者所学 㡏不休的問題，也一向被視为是我国大地 构造学中一个最复杂、最困难、最吸引人兴 趣的研究問題。由于广泛分布在奥、桂、湘、 赣等省內的前泥盆紀地层，現被証实大部分 是属于下古生代，且大多受过不同程度的变 盾，构造岩浆活动复杂，矿产䅐藏丰富，再 加上在这期間的加里东运动的特征，往往又 习慣地被地盾学界用来作为辩識这一地区属 于什么大地构造性盾的标志: 有人据此把它 划为地台区，有人据此划为地槽区，又有人 据此划为所謂“准地台䙫觟带”。因此，这就 使对加里东运动的表現及其性稹的看法，成 为整个前泥盆紀地稹問題中一个笔論焦点。 所以，如何正确地恢复其性盾，関明其与該 处目前发展阶段大地构造性稹問題的区別, 不論在理論上或实践上,都有着重大的意义。

近年来，由于大力开展大規模的区域地 盾测量工作，对分布在粤、湘、桂省境內的，三 十年来一向被訩为是元古代的龙山䒺地层, 已被証实絕大部分是属于下古生界，这就为 对本区前泥盆紀地盾构造特征的吥究，提供 了可靠的地盾依据。由于龙山㧝时代的解 决，一些人便訩为，龙山萦絕大部分是属于
下古生代, 且它包括有复理石及硬砂岩建造, 和有少量海相火山岩及加里东花南岩, 又有 紧密的全状替解、广泛的区域变稹作用，因 此本区是一个非常明显的加里东地槽褶紴 带，但同时却又梳它是属于一个准地台的大 地构造性貭。但另一些人則款为，由于吕梁 运动在本区的存在, 震旦系及下古生界地层 絕大部分属于地台型沉积建造, 加里东运动 在本区的表現也不是十分剧烈，因此本区下 古生代应属于地台沉积，而一部分地区下古 生代地层則属于地台活化的前奏，是属于-个前震旦紀古老地台的构造区。

但是,該地区的古地槽槢觟基底劣竟何 时結束？是前震旦紀基底还是加里东地槽褶 皱基底? 加里东运动的性稹及其影响如何? 这就成为我們目前迫切需要解决的問題。

\section{二 加里东运动性稹的討詥}

在粤西沿海地区，西从中越边境东至两 阳这一狄长地带, 各时代地层出露頗为完整, 特別是下古生代地层分布广泛，前人䁌把这 部分地层划分为太古代龙山索。1958 年,广 州地貭学校在合浦地区以及最近我們在:该地

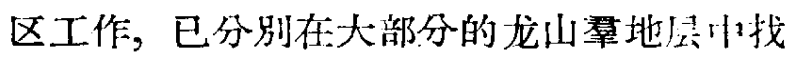
到志留紀笔石，証实这些地层大部分是属厂 志留紀的产物，种根据岩性岩相的对比及接 触关系，把一部分地县整划分为寒武奥陶紀 
（欽县黄屋屯一带）及前震旦紀 ${ }^{[1]}$ 。据野外 所自，这部分前泥琇紀地质有如下特征:

1. 前泥盆紀地层分布最广的是志留紀， 它除了与火成岩侵入接触带局部发生变稹 外,其余大部未絓变盾,或仅受輕微的变盾。

2. 下古生代的沉积是以砂岩、粘士岩为 主, 夹少量輕微变盾的千枚状粘士岩及砂砾 岩。寒武奧陶紀属于浅海相含鈴矽稹岩建造, 志留紀属于砂一粘土碎冒岩建造，沉积还稳 定。

3. 下古生代沉积升不算互愿，全厚約 5,000 米 (土)。其中寒武奧陶紀約 1,500 米, 志留紀約 3,400 米, 并沟有地槽型沉积的巨 大厚度及显著的厚度变化。

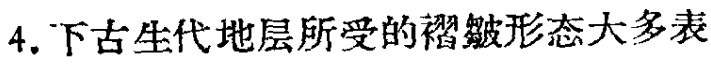
現为全状禎皱及断續形的倒轉复式袺被，分 布方向为北东一一北东东，断裂不甚发有， 主要褟解生成时代为中生代。其理由如下:

（1）下古生代志留紀与上古生代泥盆石 炭紀地层的分布方向与产状基本一致，走向 为 $N 50^{\circ}-70^{\circ} \mathrm{E}$, 倾角为 $60^{\circ}-70^{\circ}$ 。

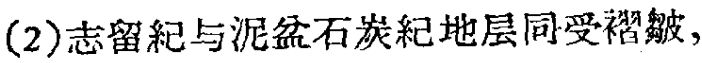

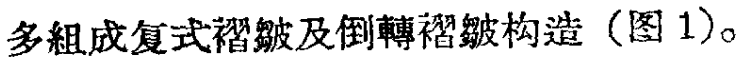

（3）在合浦䦤利坶附近, 志留紀地层(在 剑县那丽找到志留紀笔石）与中泥盆世东属

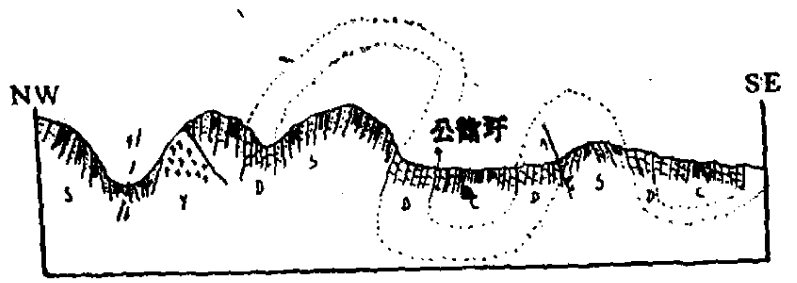

图 1 广东合浦公館附近倒轉褶擢示意图

磷灰岩表現为本行整合接触（图2）。

(4) 雷北的志留紀地层( ? ) 与下石炭紀 灰岩間有一厚約 $1-2$ 米（士）的砾岩存在， 属不整合接触，但該底砾岩成分未发現有花

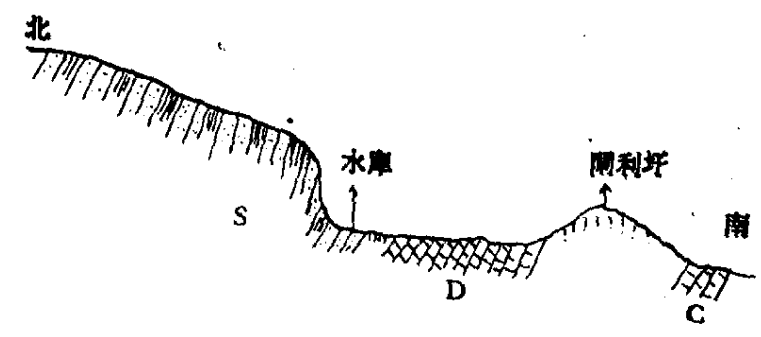

图 2 广东合浦閎利坶北坡志留䒺( ? ) 与 中上沉念統整合接触素描图

崗岩分子，更重要的是，两个地罢产状傾府 相差无几，几乎是一道同受袺餿构造影响的。

（5）从大区域分布来看，下古生代地层 与上古生代地层的区域性分布近乎一致，为 北东一唒南向。

这些材料說明，本区加里东运动表现郑 不剧烈，主要袺皱生成时代应訩为是中生代 越中运动 ${ }^{[2]}$ 及以后各次太本洋运动的結果。

5. 在雷北及阳江等地，見有花南附长岩 及片麻花湍岩等侵入到未找到化石証据的志 留紀地层中，暫誩为加里东期花崗岩。但 其上下限时代还未見有足够証据。

6. 在两阳一带，見有片啷岩、大理岩、 石英岩、結晶片岩、混合片麻岩、黑云恃及 綃云母片岩等深变稹地寻存在，它与本区浅 变稹的下古生代地层有明显的区别，与縒过 加里东期花崗岩化的地层也有不同，更重要 的是，它按岩性可与邻区广西东南部横县玉 林的前震旦紀天堂岩系相当, 故应当視为是 前震旦紀产物。但它的上限接触关系不清。

7.下古生代构造运动还缺乏地槽型典型 的大幅度下降及上升运动的特征, 相反, 以类 似地台型的大洦积升降及振遗运动較显著。

[1] 寒武奧陶紀, 张兆瑾㧱为可与黔滇寒武奥陶 紀对比, 应当䚿为是該时代。前震旦紀地层, 他也䛅为起的有一部分地层属該时代。

[2]越中运动是指三叠紀至早侏罗世間的地壳运 动,相当前人的印支远动。 
8. 上古生代泥盆、石炭紀地层属于标准 地台型沉积, 主要是砂粘土岩建造、石灰岩 建造及含煤建造，沉积稳定，厚度約 2;000 * $( \pm)$ 。褶解不強烈，断裂較为发育。

从上述前泥盆紀地稹的一些特征及各种 矛盾事实可以看出，它与典型地慒区及地台. 区特征不尽相同，故迫使我們对前人的地槽 性稹及属地台性稹的説法发生怀疑。加里东 运动在本区靽沒有翻天腹地的革命性稹, 更 不是扮演主角的造山运动。但由于在邻区确 实普遍見到泥篮紀前的不整合, 局部的加里 东花嵐岩及花崗岩化在一些地区相継发現, 故也不能忽視它的普遍性及重要性。为由于 前震旦紀地层及呂梁运动在邻区也公䚯是普 遍存在，一部分地区下古生代岩性岩相还近 似地台沉积性稹, 构造岩浆活动又不強烈, 因

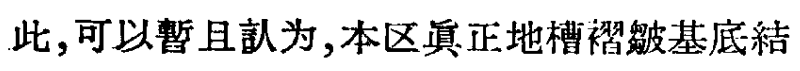
束时間应为前震旦紀，而点正的地台阶段沉 积开始于泥盆紀, 加里东动运期間則策有地 槽及地台区某种特性, 为属于牛稳定的准地 台型性盾。

\section{三“过渡阶段”的提出}

有鑑于下部古生界地层在本区及邻区桂 东南、桂西南及連滩、怀集、台开等地皆有 广泛的分布，且岩性相差不大，都普遍見到 前泥盆紀的不整合, 以及加里东花礼岩在这 些地区及邻省江西、湖南等地都陆頡有所发 現, 因此, 在华南地区加里东运动的普遍性 及重要性也应当被肯定下来。但前震旦紀变 稹岩系在华南各地皆見有沉积, 如福建西北

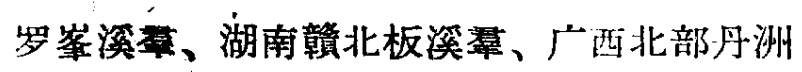

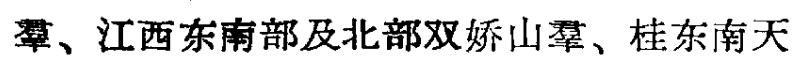

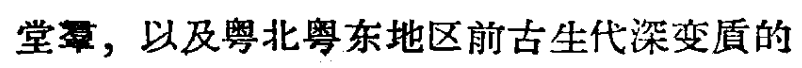
芙荅山及横坑岩組等等, 皆見有分布。这 (w)

些事实表明，吕梁运动在中国东南部也应当 被肯定下来，它是标志着地壳新的发展阶段 的开始。故这些前震旦紀的变稹岩系也应当 被視为組成本区整个古地台的禇被基底。

但由于中国古地台的基底，固結早晚不 一，程度不一，基底断裂多，古地槽潜飜迥 返作用強烈不一及构造分异作用发展不均 衡，故造成了在一些地方（如华北），早在 太古代及元古代时，地壳已开始发生构造分 异作用，出現一些小区域的“稳定地块”（前 地槽期“稳定”区，郎 X-1 区。最近有人叫所 謂“萌地台”及“原地台”，这名詞还待商椎)。 而在一些地方(如华南)，在下古生代时还处 于局部的“活动状态”。这些特点正說明在前 震旦紀时，地壳䄶不是到处普遍处于不稳定 的活动状态，也㪶不是在該时以形成現代大 陆的矽鉙外壳，而地筧普遍固結处于稳定状 态而告終。中国地売构造运动的这种特点, 現在已被愈来愈多的事实所証实了。

华南古台块是在元古代时，由中国古地 台中所分裂出来的一个地块，在这个地块的 南部南岭及舆、桂、湘、贛省边境的地区，刚好 位于华夏古台块及湘桂古台陷的边緣地带, 它除了有上述特征外，还深受华夏问及西域 向构造的控制，一些基底深大断裂早在元古 代时已发生及存在，它控制着古台块的发展 及稳定性。因此, 經呂梁运动后, 往往造成了 下古生代地层与前古生代地层呈連櫝沉积, 整个下古生代是以較大幅度沉降，連德在元 古代地槽型浅海中堆积为特征。同时在前霞 旦紀地槽发展阶段的构造运动、岩将活动及 沉积作用还有継承性的影响, 因此加里东运 动的性盾也带上了地槽殘余的影响，造成了 它的普遍存在及強烈程度不一致的特性, 而 在这期間所沉积的地昙岩相、岩性、构造岩浆 
活动等等也带有原来地槽区所深染影响的烙 印。但另一方面，它文尽量抾脫它的影响，趋 近于地台区“稳定”的性稹。我們常常在这些 地区見到: 号梁运动种不普遍存在，下古生代 地层沉积特別发育，厚度也相当厚 $(4,000-$ 7,000 *)，加里东运动在部分地区表現也较 明显,而在一些地方則表現得不显著,岩浆活 动也相当活跃，变稹作用強烈程度表現不一 致，下古生代盖层往往整伏于迫返硬結程度 低的前震旦紀基底上，常难以区別昞者開的 接触关系等特点,这些現象原是不足为奇的， 但这諮明了这些地区在下古生代期間，是从 活动的地槽区向“稳定”地台区的过渡，具有 地槽区及地台区两面特性；属于牛稳定性稹 的过渡带。經加里东运动后,到了早泥盆世, 陆相砂砾碎屑岩建造及石灰岩建造的沉积 （在邻区早泥盆統称蓮花山組或桂头岩組）, 是当时黄正地台发展阶段的开始 ${ }^{[1]}$ 。

\section{四 一些覌点和看法的初步結論}

自然发展和社会发展一样，它的发展变 化过程是由量变到稹变，由漸变到突变的过 程。而量变是稹变的准备，稹变是量变的完 成，故在发展过程中，常显示出有稹的区別 的阶段性。本区下部古生代这种发展 特征, 正是体現了由量变到稹变、部分稹变的发展 过程及阶段。本区地壳从它形成起就存在着 活动区和“稳定”区这两个对立面的矛盾斗 争，斗爭的結果，往往产生不均衡的大地构 造分异作用，引起从量变到部分稹变至完全 貭变的变化过程。中国东南部在下古生代所 固有的特征，正說明它經吕梁运动后，一 部分地区已褶㨨硬化而轉化为地台发展阶段

（如江南古台隆等地区），这是新的事物取 得支配地位的証据。而在另一些地区，在下
古生代加里东运动时，才开始发生构造分异 作用（如本区及南岭一带），未完全轉化到 地台发展阶段，然而它所具有的特征，又比 原有地槽区（前震旦紀地槽阶段）的特征更 定杂、更高級及更向前发展了一步，它在一方 面尽量摆脫“活动区”对它的影响，另一方面 又向“稳定区”过渡做好准备，到一定阶段(加 里东运动后）才引起从量到稹的根本俥專变。 这一事实也說明新的方面由小变大，旧的方 囱由大变小，逐步归于灭亡的表現。但这种 从量变到稹变,判不是突然而来的,正是由前 几阶段，特別是下古生代阶段(加里东旋迴) 的量变和部分稹变所逐步积榡的結果。地壳 这个不断发展及发展阶段的規律，反胦了地 壳每个发展过程，它既有矛盾，又有斗争; 既是对立，又是統一; 䀝有联系, 又有区別。 闰时也說明了，地壳在发展过程中在不同啲 間及空間上其构造分异作用䄶不是均衡一致 的。但它总的发展方向是按照“否定之否定” 法則，不断向前发展变化的过程。

有些人看到了本区具有地槽特征的一 面，因而強調了它是一个非常明显的加里 东地槽䙫蛁带; 而另一些人看到了它具有地 台区性稹及不像地槽特性的一面，因而又強 媩了它在这期間已完全进入地台区的发展阶 段。这㑂种看法都各有已見，各有道理，但 也有其偏見及违反客覌事物发展規律、不合 乎实际的想法。这些覌点与“泛地槽論”把地 壳发展看作簡单机械化，以及“泛地台論”把 地壳发展历史机珹地分开，看不到它們之閒 既有联系又有区別的这点是没有多大区别

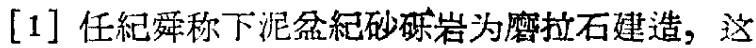
是錯誤的。1 1960 年，普莎罗夫斯基在宁杭 一带作野外覌祭时，䚯为下泥盆紀砂砾岩非 摩拉石建造，而是地台沉积底部。 
的。而下古生代牛稳定性质的过渡带的提 出，可以弥补这些缺点，从而正确地为找矿 工作提供可靠的地质依据。

\section{五 对本区現阶段大地构造性稹的看法}

必須指出，本区下部古生代加里东运动 期間这种发展特征，仅仅是說明地槽阶段結 束时間的問題，也仅是說明地売全部地稹发 展史中某一阶段的性稹，并不能以此作为鑑 刖現阶段的大地构造性稹的根据，而必須看 到本区从泥盆紀起，已进入产正“稳定”的地 台发展阶段，又从中生代中期开始，經越中 运动后，本区的古地台又經受过強烈的断裂 活化, 进入活动性质的地洼区新的发展阶段。 因此不能把地壳这种不断发展及发展阶段的 特性混淆起来, 把它称作地槽褶皱带或准地 台,或称作地台区,更不能把本区經古地台区 阶段后，再度轉化为現阶段性稹的地洼区的 事实割裂开来,把它看成是没有联系、没有区
別的一成不变的偎死的东西。同时,更不能盲 目地、机械地把不同发展阶段的特征混在一 起，与所謂世界上标准地台如北美地台及俄 罗斯地台相比，而說这地区当上古生代时不 是标准地台。具然，这样得出的結論，是不 合乎实际的，这样，也必然会导致歪曲了地 壳发展客覌事实，当然也无法真正䦐明本区 成矿規律及矿产分布規律。因此，笔者同澺 陈国达的意兒，由于一个地区的大地构浩性 盾是随着时間不断向前发展变化的，故在划 分构造区时，应当以現阶段的发展性展为准 䋲，否則会导致无原則的爭論。所以我們所 指的这个地区的准地台阶段，“和燕汲清的所 謂“准地台”根本有別, 因为后者既承訓它“原 是地台”, 又說它没有經过地台阶段，自相矛 盾，而实稹上是把地槽、地台、地洼几个阶 段混在一起的名詞。

为叙述簡便起見，我們对本区各阶段发 展过程及性稹的訩識，列出如下表:

\begin{tabular}{|c|c|c|c|c|c|c|}
\hline 时 代 & 元古代地輠期之前 & 前震旦紀 & 下古生代 & 上古代至中生代初(下) & 中生代中期以来 & 末来地貭时代 \\
\hline $\begin{array}{c}\text { 构造区 } \\
\text { 名称 }\end{array}$ & $\mathrm{x}_{-1} \stackrel{?}{\longrightarrow}$ 地 槽 & 㕷梁运动 & 地 台 区 & 加里东运动 地 台 区 & 的沄 & $?$ \\
\hline 性 盾 & 未研究清楚“稳定”区 & 活动性盾 & 稳定过渡性盾 & “稳 定” 性 稹 & 活 动 性 盾 & 来知“稳定”区 \\
\hline
\end{tabular}

最后，我們梁梁地体会到，尽管目前我 国大地构造学的研究中，存在着各种不同的 赏說与覌点,但我們訩为,要解决这些問題的 途径只有一个，那就必須思想政治掛帅，以 战无不胜的毛泽东思想为指导，实事求是地 結合中国的实际地盾情况，以辯証唯物主义 的覌点和方法加以綜合分析；才能正确地合 理地反映出地壳发展規律及關明矿”产生成和 分布規律。也只有这样，才能在最短期內形 成符合于中国实际地稹情况的新的大地构造 学派, 迅速攀登世界科学高峯。
[1] 任紀舜: 試碖中国东南部的大地构造性盾, 地盾論 評, 1960 年第 3 期。

[2] 志波清: 中国地盾构造基本特征初步总結, 地质学 报，1960 (1) 期。

[3] 中国科学院地盾研究所：中国大地构造綱要，科学 出版社, 1958 年。

[4]陈国达：地壳动定递进論，地盾学报，1959（3）期。

[5] 敖振寬: 試論中国地台南部加里东运动的影响, 1956 年。

[6]陈国达：地洼区特征及其者所謂准地台之区別，地 貭学报，(2) 1960 年。

[7] 北京地稹学院区域地稹教研組：以毛泽东忠想为指 导探索大地构造的規律,科学通报,1960年第 16 期。

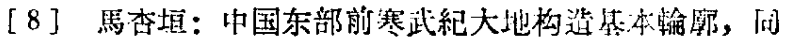
.t.

[9]陈国达：关于划分构造区的一些观点和思想方法問 題,科学道报, 1960 年第 17 期。 